\title{
Adoption of cleaner production practices by dairy farmers in southern Chile
}

\author{
Laura Nahuelhual ${ }^{1}$, María A. Engler², Bernardo Carrillo³, Víctor Moreira ${ }^{1}$, \\ and Ingrid Castro ${ }^{1}$ \\ ${ }^{1}$ Instituto de Economía Agraria and ${ }^{3}$ Instituto de Ciencia y Tecnología de los Alimentos, Universidad \\ Austral de Chile, Casilla 567, Valdivia, Chile. \\ ${ }^{2}$ Instituto de Economía Agraria, Universidad de Talca, Casilla 747 Talca, Chile.
}

\begin{abstract}
L. Nahuelhual, M.A. Engler, B. Carrillo, V. Moreira, and I. Castro. 2009. Adoption of cleaner production practices by dairy farmers in southern Chile. Cien. Inv. Agr. 36(1):97106. Rising concerns about the environmental costs of dairy production have resulted in an increasing use of farm practices that diminish negative production externalities. Yet, little empirical evidence exists regarding the factors influencing the adoption of pollution-reducing strategies by dairy farmers. In this study, we estimate a logit probability model to explain firststage adoption of capital-intensive cleaner production (CP) practices, using a sample of 100 medium and large-size dairy farms located in southern Chile. Voluntary approaches to pollution control in agriculture are relatively recent in Chile and diffusion has been slow and uneven among farmers. Only $43 \%$ of the farmers surveyed were using some CP practices at the time of the interview. The probability of adoption was found to be positively correlated with farmer's education and age, awareness of environmental regulations, the type of milk buyer, and the use of complementary CP management practices. Conversely, farm structure variables were not significant, which suggests that the adoption of $\mathrm{CP}$ practices could be responding to noneconomic motivations.
\end{abstract}

Key words: Chilean dairy sector, dairy-derived pollution, dairy farming, environmental management, technology innovation.

\section{Introduction}

Rising awareness and concern about the environmental costs of agricultural production have stimulated new interest in increasing the use of farm practices that diminish negative externalities (Fuglie and Kascak, 2001). In turn, social pressures demanding the improvement of en-

Reveived 05 August 2008. Accepted 27 November 2008. Corresponding autor: lauranaheul@uach.cl. vironmental performance and product quality have contributed to the growing development of environmental standards and regulations (Hicks and Dietmar, 2007).

Regulatory agencies, environmental groups, and concerned citizens have focused their attention on livestock operations and, more specifically, on wastewater and manure-related pollution problems resulting from large and intensive farm units. Dairy operations in particular are critical in regard to the high organic matter and nutrient levels contained in dairy effluents that 
can have detrimental effects on drinking water supplies, fish resources, and recreation (Rahelizatovo, 2002).

Different policy instruments for achieving environmental goals have been developed, which range from moral persuasion, command and control regulations by government, to economic incentives and voluntary strategies by private firms (Rahelizatovo, 2002). Among the latter, cleaner production $(\mathrm{CP})$ is considered to be a strategy addressing the generation of pollution as well as the efficient use of resources at all stages of the production process (Hicks and Dietmar, 2007). Under a CP approach to environmental regulation, the government authority calls attention to the potential damage caused by pollution and facilitates voluntary actions by firms and their associations to address that harm. Voluntary strategies like this are intended to create win-win situations, where the regulator achieves the desired environmental target with decreased enforcement costs and the regulated entities meet that target with more flexibility and efficiency (Woods et al., 2006; Daley, 2007).

In the context of dairy farming in Chile, CP involves the following management aspects contained in the $\mathrm{CP}$ public-private agreement proposal that is under negotiation: manure handling (extraction, storage, and application), disposal of waste waters (from milk-houses and sanitary installations), removal and storage of solid waste including veterinary products, use of good-quality water sources, odor management, workers' hygiene and security, and energy efficiency (CPL, 2006; Hollstein, personal communication, 2007). Hence, the successful implementation of CP plans involves a series of management practices and technologies that represent a significant investment and decrease in operational costs to farmers. In Chile, as well as in other countries, voluntary approaches to pollution control are relatively recent and the implementation of $\mathrm{CP}$ practices by dairy farmers has been slow. It can be observed, however, that a few of the farmers have started to incorporate some of the proposed practices.

In 2007, Chile had 495,465 milking cows (INE, 2007), 19.5\% less than in 1997. In turn, milk output rose from 890 million liters in 1990 to 1,871 million liters in 2007 with $69.4 \%$ (1,299 million liters) concentrated in the Los Ríos and Los Lagos regions in southern Chile (ODEPA, 2000, 2006, and 2008). Simultaneously to the rapid growth and intensification of the Chilean dairy sector, the increased loads of organic waste onto pasture lands has resulted in greater environmental impacts that affect on-site soil quality and water sources (Alfaro and Salazar, 2005). Historic over-application of phosphorous and nitrogen through commercial fertilizers and organic wastes has contributed to the potential for off-site impacts by surface runoff and by subsurface transport (Alfaro and Salazar, 2005). Despite these well recognized environmental externalities, dairy farming in Chile has been mostly immune to environmental regulation. At present there are no specific policies or instruments (mandatory or non-mandatory) aimed at inducing environmental compliance by dairy operations.

Attending to the broad goal of more sustainable agricultural development, in 2001 the Cleaner Production Policy was enacted. Under this policy, the Chilean government authority aims at promoting self-regulation by firms to address pollution reductions. The main instrument of this policy is the "cleaner production agreement" (CPA), which engages public and private agents that are linked to a specific productive sector with the goal of creating incentives required by private firms and industries to comply with existing regulations (i.e., water quality standards) (CPL, 2006). Like other negotiated agreements, a CPA is legally not-binding. Participating firms have to prepare, in collaboration with public agencies and other stakeholders, plans for pollution abatement while the government commits to abstaining from introducing new legislation (e.g., standards or taxes) unless the voluntary action fails to meet the agreed upon environmental goal (Khanna, 2001).

Government monitoring of these CPAs in some industrial sectors shows positive environmental and economic impacts resulting from the more efficient use of resources (i.e., water, energy, and other inputs) in the productive processes, improved productivity, and reduced input losses and equipment failures, which in turn are pos- 
sible through technology innovation and adaptation (CPL, 2006; Jiménez, 2007). Regarding agriculture on a broad scale, some sectors such as fruit and beef exporters and cheese and dairy processors have been very actively involved in the CPA since 2001. However, the dairy farm sector has not advanced at the same pace. Although the main dairy farmer organizations have stated that a CPA could become a differentiating attribute of their milk, also improving their competitiveness, they still have not reached a consensus with regulators and other stakeholders on how to successfully achieve environmental goals.

The goal of this study was to examine the factors affecting the joint adoption of five capital-intensive $\mathrm{CP}$ practices by a sample of 100 dairy farms located in the Los Ríos $\left(39^{\circ} 30^{\prime}-41^{\circ} 00 \mathrm{~S}\right.$ and $73^{\circ}$ $\left.5^{\prime} \mathrm{W}\right)$ and Los Lagos regions $\left(41^{\circ} 00^{\prime}-44^{\circ} 00 \mathrm{~S}\right.$ and $\left.72.56^{\circ} \mathrm{W}\right)$. Specifically, we estimated a binary logit probability model containing elements from the adoption/diffusion and farm structure theories to explain the actual use of $\mathrm{CP}$ practices by dairy farmers in southern Chile.

\section{Materials and methods}

\section{Sample and data collection}

The data came from an on-site survey of a 100 farmers in 2005. Farms were classified into medium (100 thousand to one million liters of milk per year) and large-size farms (>one million $\mathrm{L} \cdot \mathrm{year}^{-1}$ of milk) according to the stratification proposed by Smith et al. (2002), with $25 \%$ of the sample classified as medium farms and $75 \%$ as large. In 2005, these 100 farms produced 14.3\% of the total milk volume sold to the industry in the Los Ríos and Los Lagos regions. The data collected through the survey instrument included a range of questions related to the use of $\mathrm{CP}$ and Good Agricultural Practices (GAP) as well as farm structure variables and farmers' attributes. The selection of questions regarding the use of CP practices was based on various environmental protocols established by the national health and agriculture authorities (i.e., CPA and GAP protocols), the Codex Alimentarius, the United States Food and Drug Administration
(USDA) standards for grade "A" raw milk, and the EUREPGAP protocol (GAP framework of the Euro-Retailer Produce Working Group, EUREP) (Carrillo, 2006).

Considering that $\mathrm{CP}$ is a voluntary strategy and that the CPA is not yet agreed upon, many practices included in the questionnaire were not implemented at the time of the interview and were therefore excluded from the analysis. As a result, only five capital-intensive $\mathrm{CP}$ practices were selected to represent first-stage adoption of a CP program by a typical dairy farm, including: a) presence of a manure storage structure adequately designed and managed to contain manure, wastewater, contaminated runoff, and manure mixed with litter or bedding without any discharge to superficial or underground waters; b) use of a fresh water supply source for the milk-house and related installations, properly sanitized and isolated; c) presence of adequate sanitary installations for farm operators; d) use of an adequate system of disposal for the milkhouse waste waters. Milk-house waste waters contain the remainder of manure deposited in the milking parlor, udder washings, and equipment wash-water containing milk, detergents, acids and chlorine. These waters should be pumped to a properly designed liquid manure storage or stored in a separate storage system (concrete or earthen storage), and; e) use of an adequate system of disposal of waste waters from sanitary installations.

The farmers in the sample were considered to be users (adopters) of capital-intense CP practices if, at the time of the interview, they had implemented at least three of the aforementioned practices. All dairy farmers can not afford capital-intense practices because of their high startup costs. In 2005 none of the farms in the sample had implemented all five of the $\mathrm{CP}$ practices.

\section{Empirical framework and econometric techniques}

Qualitative response models, strongly linked to utility theory, aim at relating the conditional probability of a particular choice to various at- 
tributes of the alternatives, which are specific to each individual. These models are widely used in economic studies to investigate factors affecting an individual's choices from two or more alternatives (McFadden, 1974; Ameniya, 1981; Greener, 2000).

In the case of technology adoption, it is assumed that farmers make their decisions by choosing the alternative that maximizes their perceived utility. A farmer is likely to adopt a new technology or practice if the utility of adopting $\left(U_{i 1}\right)$ is larger than the utility of not doing so $\left(U_{i 0}\right)$; that is if $U_{i}^{*}=U_{i 1}-U_{i 0}>0$. Since utility is not directly observed by the researcher, it needs to be approached by an observed binary random variable (Maddala, 1992).

Defining a qualitative variable for the adoption of the new practice $I_{i}$, we have that $I_{i}=1$ if the farmer adopts and zero otherwise. The probability of adoption is given by the expression

$P_{1}=P\left(I_{i}=1\right)=P\left(U_{i}^{*}>0\right)=P\left(V_{i 1}-V_{i 0}>\varepsilon_{i 0}-\varepsilon_{i 1}\right)$

where $V_{i}$ is to the systematic component of utility related to the probability of adopting and the term $\left(\varepsilon_{i 0}-\varepsilon_{i 1}\right)$ is a random distribution term. Assuming that the stochastic elements of utility $\varepsilon_{i 0}$ and $\varepsilon_{i 1}$ are independently and identically distributed with a Weibull distribution, their difference follows a logistic distribution (Maddala, 1992). If utility is given by a linear function and if choice probabilities depend only on observed individual-specific characteristics (Judge et al., 1995), the relative odds of adopting are given by the expression

$\left(P_{1} /\left(1-P_{1}\right)\right)=\exp \left(\Sigma \beta_{i} X_{i}\right)$

Taking the natural logarithm of each side, the resulting logit model can be represented by the expression

$\ln \left[\left(P_{1} /(1-P)\right]=\Sigma \beta_{1} X_{1}\right.$

where the probability $\left(P_{1}\right)$ that a farmer adopts the practices occurs for an observed set of covariates and the $\beta_{1}$ 's are the coefficients to be estimated.
The final specification of the logit model is given in equation 1:

$\ln \left[\left(P_{I} /\left(1-P_{l}\right)\right]=\beta_{0}+\beta_{1}\right.$ Age $+\beta_{2} E d u+\beta_{3} \operatorname{Exp}+\beta_{4} V$ cow $+\beta_{5}$ Coop $+\beta_{6} M n f+\beta_{7} M i+\beta_{8} \operatorname{Reg}$,

where Age is the farmer's age, $E d u$ is his/her level of education, $\operatorname{Exp}$ is his/her experience as a dairy farmer (all measured in years), Vcow is a measure of dairy productivity expressed in annual milk production per cow, Coop is a binary variable equal to 1 if the farmer sells the milk to a dairy Cooperative, which, at the time of the survey, was the largest dairy products manufacturer within the study area (Fuller et al., 2006), and $M n f$ is a binary variable that equals 1 if the farmer sells the milk to a cheese manufacturer and 0 otherwise. Cheese processors other than the Cooperative are the second most important milk manufactures for our sample. $M i$ is a binary variable that equals 1 if the farmer has adopted various management-intensive $\mathrm{CP}$ practices. These are considered less expensive than capitalintense practices but their implementation requires higher levels of human capital by farmers. Examples are the use of an adequate system for disposal of garbage and hazardous waste, the use of a safe method for storage and removal of pesticide containers, the existence of a pest management plan, and the existence of an environmental risk management plan. Finally, Reg is a binary variable equal to 1 if the farmer is aware of environmental regulations affecting dairy farming (mainly CP policy and GAP) and 0 otherwise.

The effect of any independent variable on the probability of adoption is not given by the magnitude of the $\beta_{i}$ 's but by the marginal effects, which account for the partial change in the probability of an event (Sheikh et al., 2003). The marginal effects were obtained by taking the partial derivative of the expression of the probability with respect to a change in the variable of interest. The most commonly chosen reference point for calculating marginal effects is the mean of the variables. However, this approach is inappropriate if the matrix of covariates includes dummy variables (i.e., the mean value for a dummy variable does not correspond to any observable value). The correct approach in this 
case is to estimate the marginal effects at specific values of the dummy variable while holding continuous variables at their means. In this study, dummy variables with means less than 0.5 were set at 0 and dummy variables with means greater than 0.5 were set at 1 .

We used the correct classification of cases (adopters and non-adopters) as goodness of fit measures, which involves the number of cases assigned correctly and incorrectly on the basis of the probability of occurrence of an event (Sheikh et al., 2003; Mishra and Goodwin, 2006) and the McFadden $R^{2}$, calculated as

$R^{2} M_{C F}=1-\left(\ln \hat{L}_{u} / \hat{L}_{r}\right)$,

where $\hat{L}_{u}$ is the unrestricted log-likelihood function and $\hat{L}_{r}$ is the restricted log likelihood function (McFadden, 1974). The model was estimated using the maximum likelihood technique available within the LIMDEP 7.0 statistical package.

\section{Results and discussion}

\section{Characteristics of dairy farmers and farming systems}

Adopters of CP capital-intensive practices managed a larger number of milking and total cows. They also had larger farms and better productivity than non-users with a daily production per cow of five liters higher, which is a relevant difference in a dairy system. A higher percent of adopters also used other technologies and practices such as feedlots and management-intense $\mathrm{CP}$ practices.

Few farmers held an Animal Operations under Official Certification (AOOC) probably due to the fact that Chile just became a net exporter of dairy products in 2001. The AOOC is mandatory for farmers producing export-quality milk (Table 1).

On average, adopters were older and more educated, whereas both groups exhibited a similar experience as dairy producers. In both groups the percentage of farmers aware of the existence of environmental regulations affecting dairy farming did not reach half of the sample, being higher in the users group. This finding is relevant for regulatory institutions and policy makers, reflecting that information is not always correctly and accurately transferred, especially when it is coming from different sources such as the GAP, domestic and international standards, and CP policy, among others.

\section{Model estimation results}

The model correctly predicted and classified $81 \%$ of the farmers. The McFadden $R^{2}$ was 0.11 , which, along with the percentage of correct predictions, indicates that the model has reasonably good explanatory power.

The variable Age had a positive and significant coefficient, suggesting that older farmers are potentially more aware and concerned about pollution damage arising from dairy farming, thus increasing the probability of adopting $\mathrm{CP}$ practices. Yet, its impact on the probability was low, as indicated by the marginal effect coefficient (0.015). Edu was also positive and significant, which is consistent with the adoption/diffusion theory, where innovators are better educated than late adopters (Padel, 2001). Its marginal effect coefficient indicates that an additional year of formal schooling raises the probability of adoption by $10 \%$. On the contrary, the coefficient on Exp did not influence the probability of adoption (Table 2).

Milk productivity (Vcow) is used here as a farm structural factor. This variable, contrary to our expectations, was statistically not significant suggesting that productivity does not necessarily influence the probability of adoption. We tried other structural factors such as farm size, but they were not significant, suggesting that adoption of capital-intense CP practices may be related to non-economic factors. Burton et al. (1997) found non-economic factors to be widely present in the decision of farmers to change to organic systems, which may reflect the importance of life-style related goals to organic grow- 
Table 1. Characteristics of dairy operations and farmers.

\begin{tabular}{|c|c|c|}
\hline Characteristics of dairy operations & $\begin{array}{l}\mathrm{CP}^{1} \text { users } \\
\text { (adopters) }\end{array}$ & $\begin{array}{l}\mathrm{CP}^{1} \text { non-users } \\
\text { (non-adopters) }\end{array}$ \\
\hline Farmers, no. & 43 & 57 \\
\hline Average of total cows, no. & 373 & 251 \\
\hline Average of milking cows, no. & 310 & 216 \\
\hline Average milk production per cow, $L \cdot$ day $^{-1}$ & 23.5 & 17.8 \\
\hline Milking/total cows ratio & 0.83 & 0.86 \\
\hline Total farm area, ha & 222.9 & 189.5 \\
\hline Existence of other dairy management practices and technologies & $\%$ & $\%$ \\
\hline $\mathrm{AOOC}^{2}$ & 16.3 & 8.8 \\
\hline Feedlot & 81.4 & 70.2 \\
\hline Management-intensive $\mathrm{CP}$ practices & 51.2 & 22.8 \\
\hline \multicolumn{3}{|l|}{ Farmers characteristics } \\
\hline Average age, years & 60.3 & 53.1 \\
\hline Average formal education, years & 15.5 & 14.7 \\
\hline Average experience as dairy farmer, years & 8.5 & 8.4 \\
\hline Awareness of environmental regulations by farmers & 39.5 & 38.6 \\
\hline
\end{tabular}

ers. Experiences with a diverse set of voluntary environmental programs show that some firms are motivated to act out of a combination of civic duty, good public relations, market differentiation and a apprehension for more stringent government regulation, which is contrary to the image of profit-seeking firms that pay no attention to the external impacts of their operation (May, 2005).

Selling to a Cooperative (Coop) was an important factor in explaining the probability of being a CP user with a marginal effect of 0.33 . For many years this institution has formed alliances among cooperatives and dairy farmers in Chile, which has given it great market strength in the southern part of the country (Fuller et al., 2006). Moreover, producers in the southern regions have a very favorable opinion of the Cooperative, in part because of its history in southern Chile but also because of the perception that the milk prices and assistance offered are superior to those offered by other firms (Fuller et al., 2006). Selling to cheese manufacturers also had a positive influence on adoption, as indicated by the positive and significant parameter on Mnf and a marginal effect of 0.55 . It is important to remark that in Chile dairy processors do not provide explicit price incentives to farmers for adopting environmentally friendly practices. Yet, the Cooperative is investing more than the average industry in incorporating safety and environmental standards into its production processes, which is used as a competitive strategy. Therefore, it is likely that the Cooperative buys milk from producers that follow stricter standards in order to keep value along the chain. This strategy could motivate farmers to adopt CP practices in order to continue selling to the Cooperative in the long run.

As expected, the use of complementary management-intensive $\mathrm{CP}$ practices $(\mathrm{Mi})$ was positive and statistically significant, increasing the 
Table 2. Logit model parameters and goodness of fit measures.

\begin{tabular}{|c|c|c|c|}
\hline Variable & \multicolumn{2}{|c|}{ Parameter estimates $^{1}$} & Change in probability \\
\hline Constant & $-15.05 * * *$ & $(4.39)$ & -3.68 \\
\hline Age & $0.62 \mathrm{E}-01 *$ & $(0.32 \mathrm{E}-01)$ & $0.15 \mathrm{E}-01$ \\
\hline Edu & $0.43^{* *}$ & $(0.19)$ & 0.10 \\
\hline Exp & $-0.78 \mathrm{E}-01$ & $(0.56 \mathrm{E}-01)$ & $-0.19 \mathrm{E}-01$ \\
\hline Vcow & $0.20 \mathrm{E}-03$ & $(0.12 \mathrm{E}-03)$ & 0.49E-04 \\
\hline Coop & $3.63 * * *$ & $(1.23)$ & 0.33 \\
\hline Mnf & $2.85^{* *}$ & $(1.17)$ & 0.55 \\
\hline $\mathrm{Mi}$ & $1.39 * *$ & $(0.69)$ & 0.33 \\
\hline Reg & $2.19 * *$ & $(0.95)$ & 0.48 \\
\hline Unrestricted log likelihood & \multicolumn{2}{|l|}{-34.92} & \\
\hline Restricted log likelihood & \multicolumn{2}{|l|}{-54.44} & \\
\hline Chi-squared (8 df) & \multicolumn{2}{|l|}{$39.04 * * * *$} & \\
\hline McFadden $R^{2}$ & \multicolumn{2}{|l|}{0.11} & \\
\hline \multirow[t]{2}{*}{ Observations $^{2}$, no. } & \multicolumn{2}{|l|}{79} & \\
\hline & \multicolumn{2}{|r|}{ Predicted, $\%$} & Correct \\
\hline Observed & Non-adoption & Adoption & Predictions, $\%$ \\
\hline Non-adoption & 37 & 6 & 86.04 \\
\hline \multirow[t]{2}{*}{ Adoption } & 9 & 27 & 75.00 \\
\hline & & Overall & 81.01 \\
\hline
\end{tabular}

${ }^{1}$ Standard error between brackets, and asterisks: ${ }^{*}=\mathrm{p}<0.1 ; * *=\mathrm{p}<0.05 ; * * *=\mathrm{p}<0.01,{ }^{* * * *} \mathrm{p}<0.0001$.

${ }^{2} 21$ observations were lost in the estimation due to item non-response problems.

probability of being a user of capital-intensive practices by $33 \%$. Although a low percentage of farmers knew the environmental regulations (Table 1), the coefficient on $R e g$ was positive and significant, increasing the probability of using CP practices by $48 \%$.

It is important to highlight that the adoption of $\mathrm{CP}$ practices under voluntary regulation differs in many respects from other innovations that have been the focus of early adoption studies. These differences have been highlighted by Padel (2001) for the case of organic farming adoption. First, CP (alike to organic farming) is a complex innovation that requires a systemwide change on the part of the farmer. Pollution prevention requires structural investment that involves changing the operation and improving the environmental performance of the final product throughout the production process
(Gavronski et al., 2008), which is why innovation can be seriously constrained by financial capacity. In our sample, users of capital-intense CP practices coincide with farmers that hold larger farms and herds (Table 1).

Secondly, although pollution prevention can generate significant economic benefits in the form of reduced losses from excessive materials and energy consumed, such gains are usually not so obvious to the farmer. The recognition of these benefits will depend on the farm manager treating the environment as an operational component that must be integrated in all operational decisions rather than as an independent external constraint (Gavronski et al., 2008). Furthermore, non-economic incentives can arise, which may explain the lack of importance of farm structural factors. Studies by Lowe et al. (1997) and Ward et al. (1998) address the important dis- 
tinction in attitudinal norms that divide farmers into more radical, proactive environmental managers, and more traditionalists with respect to their perceived environmental responsibilities. The more proactive farmers exhibit a sense of responsibility and a need for precautionary avoidance of environmental harm, while traditionalists are more accepting of environmental harm and tend to see it as an inevitable result of agricultural production.

Thirdly, CP is an information-based innovation and, therefore, the availability of information is likely to be crucial in the diffusion process. In Chile, however, the technical and economic data required by farmers to make informed decisions has not been developed in great detail.

Finally, the adoption of $\mathrm{CP}$ programs at the farm level is likely to be policy induced. The knowledge of policy regulations was a significant variable in our model even though few farmers were aware of them. Recent literature on technological change and the environment agrees that environmental regulation is likely to stimulate innovation and adoption of technology, which would facilitate environmental compliance (Khanna, 2001; Kerr and Newell, 2003). Furthermore, regulated entities are more likely to put up with regulation when they believe it is appropriate, fair, equitable in implementation, efficient, relevant and necessary (Winter and May, 2001).

For a representative sample of medium and large size dairy farms of southern Chile in 2005, we can validate some hypotheses proposed in the theoretical and empirical literature on technology adoption. Age and education increase the probability of a farmer being a user of cleaner production practices. Conversely, the years of experience as a dairy farmer did not influence such decisions. There is no evidence to support any significant effect of farm structure variables (i.e., output per cow) in the decision of adoption. It is possible then, that non-economic factors can influence farmers' choices.
The type of manufacturer that the farmers sell their milk to had a significant effect on the decision of using CP practices. Finally, awareness of environmental regulations affecting dairy farming also enhanced adoption, a result that is plausible since firms faced with pressures or incentives resulting from environmental policies may be more committed to better environmental performance in order to stay competitive.

The probability model estimated in this study provides valuable information about the variables that could be influencing the first-stage adoption of CP practices for this sample of dairy farmers. The model's results contribute to understanding the motivations and attributes that lead farmers to address pollution and potential environmental harm, which is relevant for judging the promise and limitations of a CP strategy as a voluntary approach to environmental regulation.

We expect these results to provide policy makers and regulatory agencies with useful information to further encourage $\mathrm{CP}$ adoption among dairy farmers. This is particularly relevant in a scenario where agriculture will undoubtedly come under increasing scrutiny with regards to its environmental impacts. Further regulation is inevitable unless it can be demonstrated that farmers, as main examples of land stewards, are already behaving in environmentally responsible ways.

\section{Acknowledgments}

The authors wish to thank Fondo de Fomento al Desarrollo Científico y Tecnológico, FONDEF, (Grant DO3i-1151) for its financial assistance to this research. We also thank Mr. Humberto Navarro from INIA (Instituto de Investigaciones Agropecuarias) for his support in the survey application and Miss Brenda Roman for her editorial assistance. 


\section{Resumen}

\section{Nahuelhual, M.A. Engler, B. Carrillo, V. Moreira y I. Castro. 2009. Adopción de prácticas de producción limpia en predios lecheros del sur de Chile. Cien. Inv. Agr. 36(1):97-106.} La creciente preocupación por los costos ambientales generados por la producción lechera, se ha traducido en un mayor uso de prácticas que disminuyan la generación de externalidades negativas. Sin embargo, existe escasa evidencia empírica en relación con los factores que determinan el nivel de adopción de tales prácticas en el caso de predios lecheros. En este estudio se estimó un modelo de probabilidad (logit) para explicar la adopción de prácticas de producción limpia (PL) intensivas en capital, para una muestra de 100 explotaciones lecheras de mediano y gran tamaño del sur de Chile. En Chile, los enfoques voluntarios para el control de la contaminación en la agricultura, como es el caso de la PL, son relativamente recientes y su difusión ha sido lenta y desigual entre los agricultores. Para el caso de esta muestra, sólo el $43 \%$ de los agricultores utilizaba prácticas de PL en el momento de la entrevista. Los resultados indican que la probabilidad de adopción presenta una correlación positiva con la educación del agricultor y la edad, el conocimiento de las normativas ambientales, el tipo de comprador de leche, y el uso de prácticas complementarias de PL basadas en manejo. Por el contrario, las variables relacionadas con la estructura predial no fueron estadísticamente significativas, lo que sugiere que la adopción de prácticas de PL puede responder a motivaciones no económicas.

Palabras clave: Contaminación agropecuaria, gestión ambiental, innovación, manejo de lecherías, tecnológica, sector lácteo chileno.

\section{References}

Alfaro, M., and F. Salazar. 2005. Ganadería y Contaminación Difusa, Implicancias para el Sur de Chile. Agricultura Técnica (Chile) 65:330-340.

Ameniya, T. 1981.Qualitative Response Models. A survey. Journal of Economic Literature 19:14831536.

Burton, M., D. Rigby, and T. Young. 1997. Why do UK organic horticulture producers adopt organic techniques? NENOF 6:7-10.

Carrillo, C. 2006. Comportamiento de las Variables de Producción Limpia en Predios Lecheros de Alta Producción de la Décima Región. Tesis Lic. Ing. Alimentos. Facultad de Agronomía, Universidad Austral de Chile. Valdivia, Chile. 121 p.

CPL. 2006. Producción Limpia, Prevención y Eficiencia. Consejo Nacional de Producción Limpia (CPL). Santiago, Chile. www.pl.cl. (Accessed on: March 10, 2007).

INE. 2007. Censo Agropecuario. 2007. Vacas destinadas a la producción de leche en explotaciones agropecuarias y periodo de ordeña según tamaño de las explotaciones. Instituto Nacional de Estadística (INE). Santiago, Chile. www.ine.cl. (Accessed on: December 4, 2008).

Daley, D. 2007. Voluntary approaches to environmental problems: exploring the rise of nontraditional public policy. The Policy Studies Journal 35:65-180.

Fuglie, K., and C. Kascak. 2001. Adoption and diffusion of natural-resource-conserving agricultural technology. Review of Agricultural Economics 23:386-403.

Fuller, F., J. Beghin, M. Boland, A. Babcock, and W. Foster. 2006. Global Prospects for Dairy in Argentina and Chile: Evidence from Field Visits and Model Simulations. MATRIC Briefing Paper; 06-MBP 11. Iowa. United States. 80 p.

Gavronski, I., G. Ferrer, and E. Laureano. 2008. ISO 14001 certification in Brazil: motivations and benefits. Journal of Cleaner Production 16:87-94.

Greener, W. 2000. Econometric Analysis. Fourth edition. Prentice Hall, Inc. Upper Saddle River, New Jersey, USA. 995 pp. 
Hicks, C., and R. Dietmar. 2007. Improving cleaner production through the application of environmental management tools in China. Journal of Cleaner Production 15:395-408.

Jimenez, O. 2007. Voluntary agreements in environmental policy: an empirical evaluation for the Chilean case. Journal of Cleaner Production 15:620-637.

Judge, G., W. Griffiths, R. Hill, H. Lutkepohl, and T. Lee. 1985. The Theory and Practice of Econometrics. Second ed. John Wiley and Sons. NY, USA. 1019 p.

Kerr, S., and R. Newell. 2003. Policy-induced technology adoption: evidence from the U.S. lead phasedown. The Journal of Industrial Economics 3:317-343.

Khanna, M. 2001. Non-mandatory approaches to environmental protection. Journal of Economic Surveys 15:291-324.

Lowe, P. J. Clark, S. Seymour, and N. Ward .1997. Moralizing the Environment: Countyside change, farming and pollution. Routledge Taylor and Francis Group. UCL. 224 p.

Maddala, G. 1992. Limited-dependent and qualitative variables in econometrics. Cambridge University Press, Cambridge, UK. 373 p.

May, P. 2005. Regulation and compliance motivations: examining different approaches. Public Administration Review 65:31-44.

McFadden, D. 1974. Conditional Logit Analysis of Qualitative Choice Behavior. Pages 104-142. In: P. Zarembka (ed.), Frontiers in Econometrics. Academic Press, NY, USA.

Mishra, A., and B. Goodwin. 2006. Revenue insurance purchase decisions of farmers. Applied Economics 38:149-159.

ODEPA. 2000. Estadísticas y precios. Industria Láctea. Boletín de la leche 2000. Oficina de Estudios y Políticas Agrarias (ODEPA). www.odepa.cl. (Accessed on: March 20, 2007).

ODEPA. 2006. Estadísticas y precios. Industria Láctea. Boletín de la leche 2006. Oficina de Estudios y Políticas Agrarias (ODEPA). www.odepa.cl. (Accessed on: April 5, 2007).

ODEPA. 2008. Boletín de la leche. www.odepa.cl. (Accessed on: March 25, 2008).

Padel, S. 2001. Conversion to organic farming: a typical example of the diffusion of an innovation? Sociologia Ruralis 41:41-61.

Rahelizatovo, N. 2002. Adoption of Best Management Practices in the Louisiana Dairy Industry. Dissertation, Department of Agricultural Economics and Agribusiness, Louisiana State University. Baton Rouge, LA, USA. 198 p.

Sheikh, A., T. Rehman, and C. Yates. 2003. Logit models for identifying the factors that influence the uptake of new 'no-tillage' technologies by farmers in the rice-wheat and the cotton-wheat farming systems of Pakistan's Punjab. Agricultural Systems 75:79-95.

Smith, R., V. Moreira, and L. Latrille. 2002. Caracterización de sistemas productivos lecheros en la $\mathrm{X}$ región de chile mediante análisis multivariable. Agricultura Técnica (Chile) 62:37-395.

Ward, N. J. Clark, P. Lowe, and S. Seymour. 1998. Keeping matter in its place: Pollution regulation and the reconfiguring of farmers and farming. Environment and Planning A 30:1165-1178.

Winter, S., and P. May. 2001. Motivation for compliance with environmental regulations. Journal of Policy Analysis and Management 20:675-698.

Woods, M., S. Thornsbury, K. Curry, and R. Weldon. 2006. Regional trade patterns: the impact of voluntary food safety standards. Canadian Journal of Agricultural Economics 54:531-553. 